Anabela Branco de Oliveira Universidade de Trás-os-Montes e Alto Douro literaturaecinema@gmail.com

\title{
$O$ cineasta e a cidade: Manoel de Oliveira e O Porto
}

\section{Resumo:}

Manoel de Oliveira protagoniza uma forte, inexplicável e inadjetivável ligação ao Porto. Projeta, em Douro Faina Fluvial (1931), Aniki-Bóbó (1942), O Pintor e a Cidade (1956), e Porto da minha Infância (2001) uma relação especial entre a cidade e o universo cinematográfico. O Porto de Manoel de Oliveira torna-se um discurso fílmico, num percurso estético sem fronteiras entre ficção e documentário. O Porto constitui-se como a arquitetura do próprio filme tornando-se personagem, título, espaço máximo de reflexão arquitetónica e cinematográfica. É um Porto labiríntico de imagens, uma cidade transformada pelas múltiplas câmaras cinematográficas de um só Mestre.

Palavras-chave: Manoel de Oliveira, cidade, cinema, arquitetura, Porto.

\section{Abstract:}

\section{The film director and the city: Manoel de Oliveira and Porto}

Manoel de Oliveira brings about a strong, inexplicable and a connection impossible to define to Porto. He casts, in Douro Faina Fluvial (1931), Aniki-Bóbó (1942), O Pintor e a Cidade (1956), and Porto da minha Infância (2001) a special relationship between this city and the universe of movies. The Porto of Manoel 
de Oliveira becomes a filmic discourse, an aesthetic journey without boundaries between fiction and documentary. It's a city established as the architecture of the film becoming the character, title, maximum space of architectural and cinematic reflection. It is a labyrinthine Porto of images, a city transformed by the multiple film cameras from a single Master.

Keywords: Manoel de Oliveira, city, cinema, architecture, Porto.

Manoel de Oliveira protagoniza uma forte, inexplicável e inadjetivável ligação ao Porto. Projeta, em Douro Faina Fluvial (1931), Aniki-Bóbó (1942), O Pintor e a Cidade (1956) e Porto da minha Infância (2001) uma relação especial entre a cidade e o universo cinematográfico.

Os espaços reais são cenários e, ao mesmo tempo, sujeitos da própria história. São espaços sociais e culturais escolhidos pelo cineasta onde o imaginário e o real se encontram no espaço do habitável. Em Manoel de Oliveira, a cidade do Porto apresenta-se, simultaneamente metamorfoseada, desfigurada, por vezes irreconhecível, seletiva e parcial porque é alvo de um olhar cinematográfico. As ruas e os espaços emblemáticos estabelecem a dualidade das representações urbanas. A arquitetura portuense de Manoel de Oliveira é um espaço de memória e de imaginação na escolha de planos, ritmos e enquadramentos. É um lugar de passagem, de paródia e de fascinação que acolhe, afasta e hierarquiza. O território urbano de Manoel de Oliveira é um espaço de encontro, de solidão, de pessoas e de edifícios. O seu Porto é imaginário, quimérico, desejado e repelido. Um Porto intrínseco ao cineasta, numa entrevista a Yan Lardeau: “J'ai filmé ma ville pour des raisons sentimentales, par sympathie naturelle. C'était des choses que je connaissais bien, ce qui est important aussi. Les lieux m'étaient familiers" [Lardeau, Tancelin, Parsi, 1988: 66]. 


\section{Espaços de história e de identidade}

$\mathrm{Na}$ relação entre o Porto e o olhar cinematográfico de Manoel de Oliveira há uma profusão de questões, de planos e de percursos de montagem.

Em Porto da Minha Infância, Manoel de Oliveira escolhe os espaços sociais e culturais que o marcaram enquanto jovem e enquanto cineasta. Porto da Minha Infância e $O$ Pintor e a Cidade projetam um percurso, no presente e no passado, pelas ruas e estátuas que enunciam a identidade histórica da cidade. Nos dois documentários, a Avenida dos Aliados é alvo dos olhares de D. Pedro IV e de Almeida Garrett, em $O$ Pintor e a Cidade e introduzem momentos históricos (as lutas liberais), em Porto da Minha Infância. A identidade histórica relaciona-se com as ruas da cidade: a rua 9 de julho, inevitavelmente ligada ao desembarque das tropas de Dom Pedro, em 1832, e a rua 31 de janeiro ligada ao movimento resistente numa primeira tentativa de implantação da República. O Pintor e a Cidade continua a saga dos movimentos portuenses de luta e de resistência na análise dos baixos relevos e das gravuras representativas do desastre da Ponte das Barcas, ocorrido durante as invasões napoleónicas.

Almeida Garrett olha a Avenida num contra campo extenso em $O$ Pintor e a Cidade e define-se como imagem à voz off de um dos seus poemas em Porto da Minha Infância. A câmara percorre ruas largas e praças movimentadas ao lado de ruelas estreitas de ritmos intensos e lentos. A Estação de São Bento enuncia o seu passado de ferro e de cristal em $O$ Pintor e a Cidade, explorando a luz dos vitrais e azulejos e a agitação humana que os contempla.

Manoel de Oliveira escolhe, nos dois documentários, o Porto dos espaços míticos, como a Torre dos Clérigos e o Porto dos espaços misteriosos dos clubes noturnos em Porto da Minha Infância. Os planos panorâmicos das fachadas exteriores conduzem-nos aos ambientes musicais e à ficcionalização das atitudes nos interiores do Palace ou do Clube do Porto. Os jardins da Cordoaria, do Palácio de Cristal e de Santa Catarina tornam-se um espaço obrigatório de recordações 
de enamoramento e de fascínio por primas, flores e automóveis, definidos em imagens de arquivo de um palácio desaparecido. Os cafés, apresentados em planos fixos de fotografias antigas a preto e branco, ou sugeridos em ténues movimentos de câmara, sugerem a tertúlia e a criatividade: o café Palladium representa o seu arquiteto, Marques da Silva; o Café Central projeta a relação com Adolfo Casais Monteiro e o Magestic enuncia a criação, em 1934, do argumento de $O s$ Gigantes, o filme que nunca foi rodado.

A Confeitaria Oliveira percorre, nos planos fixos da foto e no olhar ficcionalizado do cineasta, a noção proustiana da passagem do tempo e o caráter efémero do prazer dos doces transformados em inestéticas peças de roupa.

\section{Planos, enquadramentos e pontes}

Os enquadramentos, as plongées e contre-plongées espelham a cidade dos momentos de tensão, de imaginação e de bulício exterior em Douro Faina Fluvial, Aniki-Bóbó e O Pintor e a Cidade e justificam a memória e a magia do cinema em Porto da Minha Infância. A cidade é constantemente olhada por múltiplos olhares cinematográficos.

O Magestic é espaço para escrita de um argumento e a ligação do cineasta com a cidade continua com as imagens do High Life "a primeira sala de cinema em edifício próprio", espaço de magia e de inocências do público que, por sua vez, conduzem às imagens do seu sucessor, o Cinema Batalha. E, no cinema, o Porto constrói uma identidade própria. A rua de Santa Catarina torna-se, no passado, protagonista, através das suas costureirinhas, do primeiro filme de Aurélio da Paz dos Reis. Manoel de Oliveira confere-lhe um novo protagonismo quando nos mostra o mesmo Aurélio a filmar a saída dos operários das obras do Porto 2001, Capital Europeia de Cultura.

Manoel de Oliveira seleciona espaços protagonistas de planos e enquadramentos. Aniki-Bóbó foi rodado em cenários naturais nas 
margens do Douro, no Porto e em Gaia. O cineasta aponta para todos os lados da cidade: os novos, os velhos, os comerciais, os turísticos, os ribeirinhos e os mais rurais: outras arquiteturas e outros movimentos humanos. A ribeira representa uma outra cidade: são as plongées, as ruas e as escadarias de Aniki Bóbó.

$\mathrm{O}$ ritmo da cidade que acorda, a simultaneidade dos gestos e dos movimentos, a força criativa de Vertov espelha-se, em $\mathrm{O}$ Pintor e a Cidade, no toque da alvorada, no recorte em nascimento solar da Torre dos Clérigos, na torre da fábrica e no percurso dos trabalhadores em direção ao trabalho. Em todos os filmes analisados, o cineasta projeta os dois olhares do Porto num contínuo dissipar de diferenças entre o Porto visto do cais de Gaia ou do Porto refletido no seu interior. No diálogo entre os dois espaços inevitáveis sublinha-se a carga simbólica e também inevitável das pontes. E esse mesmo universo torna-se a alavanca de um projeto com Jean Rouch realizado aquando da vinda deste para apadrinhar o doutoramento honoris causa atribuído a Manoel de Oliveira pela Faculdade de Arquitetura da Universidade do Porto:

Em menos de cinco minutos, o projecto ficou concluído: Manoel escreveria um poema que filmaríamos com os nossos companheiros Bernard, Jerome e François. E como em todos os sonhos infantis, nós realizámo-lo em menos de uma semana, percorrendo as margens do Douro a pé, de carro, de helicóptero, voltando atrás, perseguindo nuvens maravilhosas. Eu e Manoel gritando as estâncias do poema inspirado pelo vento, o rio e a amizade:

Ponte!

Braço ao encontro de braço.

Braços estendidos

Como um punhado de mãos amigas

Assim sou eu para contigo

E vamos por este rio,

que é Durius

que é Porto

que é Douro. [Baecque, Parsi, 1999: 30] 
Porto da Minha Infância apresenta travellings pela ponte D. Luís e um travelling pelo novo viaduto da marginal ribeirinha. O Pintor e a Cidade está repleto de planos geométricos da mesma ponte, de observações cinematográficas e pictóricas da ponte D. Maria e de planos de detalhe e de homenagem de um contacto com o passado definido no desastre da Ponte das Barcas. A geometria da ponte orienta a velocidade e a simetria dos enquadramentos em Douro Faina Fluvial, transformando-a num intenso protagonismo e omnipresença. Aliado a uma das pontes, o comboio e os espaços por ele percorridos denunciam uma outra cidade. Em $O$ Pintor e a Cidade, o comboio atravessa as casas em constante movimento e recria espaços míticos como a Estação de S. Bento. Em Aniki-Bóbó, torna-se a alavanca narrativa da tensão, da dúvida e da culpa.

\section{Torres, casas e escadarias}

As torres e os detalhes barrocos de igrejas e estátuas denunciam um Porto de pináculos vistos de Gaia e observados ao fundo de ruas e praças: torres e sinos ocupam planos e projetam olhares entre o passado e o presente. Um olhar que escolhe essencialmente o universo inconfundível da Torre dos Clérigos em panorâmicas e detalhes de cinzel e o Porto da Minha Infância define o esbatimento de fronteiras entre documentário e ficção na análise da escalada observada pelo jovem Oliveira. Nesse processo de montagem paralela, a torre torna-se o símbolo do inatingível e da coragem observada e adorada pela população. Os planos de detalhe protagonizam, nos três documentários, estátuas, inscrições, detalhes de granito com especial incidência interpretativa na sequência da escultura de Soares dos Reis em Porto da Minha Infância.

No percurso dos espaços, a carga seletiva de Manoel de Oliveira confere protagonismo ao emaranhado das casas. Porto da Minha Infância inicia a sequência projetando a casa como um elemento 
primordial do olhar sobre o mundo - "o fantasma da casa onde nasci”. É a relação da casa com o tempo, com a memória e com a cidade. Douro Faina Fluvial projeta a geometria das casas em plongées e planos panorâmicos; telhados, janelas e chaminés definem cargas e descargas, descansos efémeros e carregamentos pesados, velocidade e dureza do trabalho. O Pintor e a Cidade enuncia o emaranhado altivo e veloz de monumentos e edifícios emblemáticos e o emaranhado colorido e estranho das casas populares da Ribeira inevitavelmente ligadas ao movimento ondulante e também colorido da roupa a secar, omnipresente em todos os filmes analisados. Ao lado das casas, outra realidade portuense define planos e enquadramentos: as inconfundíveis escadarias que marcam a dúvida, a curiosidade, a perseguição e o encantamento em Aniki-Bóbó: o lojista segue os miúdos ao longo das escadarias na sequência do acidente do Eduardito, os miúdos correm e divertem-se nas escadarias e a escadaria final é o espaço privilegiado da consagração da amizade entre Carlitos, Teresinha e a boneca da Loja das Tentações.

\section{A metamorfose da imagem criativa}

Mas o Porto de Manoel de Oliveira é, sobretudo, uma cidade de metamorfoses que constroem a estrutura da imagem criativa.

$\mathrm{E}$ as metamorfoses vão sendo multiplicadas e multiplicantes: é a metamorfose do travelling noturno, com um violino e um violoncelo, numa câmara de memória subjetiva e da cor que define o contraste das imagens do presente e do passado; é o vaguear pelas ruas escuras da cidade velha, com os amigos, "dando largas à imaginação", nas memórias da juventude do cineasta em Porto da Minha Infância, a metamorfose das intertextualidades quando, no mesmo filme, na voz off da memória, surgem excertos de Douro Faina Fluvial e Aniki-Bóbó. Projeta a metamorfose cinematográfica quando a garagem da antiga casa, em Porto da Minha Infância, se transforma 
num laboratório de revelação de película e, quando se assume, na voz off de Oliveira que "as memórias ficam sepultadas mas o cinema mantém-nas vivas". É a metamorfose de percursos noturnos de "polícias e ladrões" de Aniki-Bóbó. É a metamorfose rítmica e inquieta de Douro Faina Fluvial durante os travellings laterais pelas casas da Ribeira e o ritmo dos processos arquitetónicos no enquadramento da ponte. É a metamorfose das casas em plongées, contre-plongées, velocidade e movimento conferindo protagonismo à cidade. Nele, a metamorfose da geometria estabelece o percurso do formigueiro humano nas texturas simétricas de sardinhas, douradas, feixes de tubos, rolos de cabos e ripas de madeira aliados aos padrões dos novos edifícios dos anos 50 em três planos inesquecíveis de $\mathrm{O}$ Pintor e a $\mathrm{Ci}$ dade. É a metamorfose da geometria e da carga simétrica do padrão na sequência do acidente em Douro Faina Fluvial. É a metamorfose do plano panorâmico vertical do chafariz no mesmo alinhamento da palmeira, da montagem que alterna a árvore tremebunda e quase sem folhas e a omnipotência arquitetónica do estádio e do plano oblíquo dos padrões dos edifícios dos anos 50 em $O$ Pintor e a Cidade. É o confronto entre janelas, ruas estreitas, trabalhos duros e roupa a secar na Ribeira e a duração dos planos e o ritmo de montagem na imponência do barroco e do granito.

Em $O$ Pintor e a Cidade, a câmara percorre o emaranhado das casas, os detalhes do sino e da rosácea, os planos panorâmicos verticais das igrejas, das estátuas e das janelas. A câmara analisa e recolhe a carga arquitetural da cidade. $\mathrm{O}$ pintor olha o rio, os telhados e as roupas a secar fazem o mesmo. O contraste entre o voo dos pássaros e a omnipresença estática da igreja é o contraste entre a imobilidade dos edifícios e o bulício da cidade. Na montagem, esse contraste desaparece e as estátuas apontam, olham e dirigem o movimento das pessoas. O Condestável aponta a liberdade e o movimento dos indivíduos na rua. Na sequência seguinte, o movimento da população é dirigido pelas estátuas. Elas olham e apontam para a esquerda e para a direita, para baixo e para cima e o formigueiro de gente repete o mesmo equilíbrio. Manoel de Oliveira, numa entrevista a Yan Lardeau, define a carga estética destes jogos de liberdade: “Quand j'ai réalisé mes 
premiers documentaires, il y avait consciemment ou inconsciemment un désir refoulé de fiction, j'avais tendance à intervenir, à mettre en scène, à faire des petits essais" [Lardeau, Tancelin, Parsi, 1988: 69].

O protagonismo das estátuas projeta o domínio da arquitetura sobre o movimento humano da cidade e concretiza, neste olhar cinematográfico, uma eventual arquitetura condicionante.

\section{A dualidade das representações urbanas}

Ruas e espaços emblemáticos estabelecem a dualidade das representações urbanas. Em O Pintor e a Cidade, Manoel de Oliveira estrutura a geometria das casas, os movimentos de câmara ao longo do granito, os planos panorâmicos do barroco, os enquadramentos e as geometrias dos pilares, numa montagem exigente que os coloca num intenso contraste com o movimento humano. A estrutura metálica da ponte projeta uma imensidão fria e cinzenta em contraste com o lado colorido e humano dos remos e dos barcos. A estrutura estática contrapõe-se à intensidade e à atividade da população ribeirinha. A dureza da construção granítica contrasta com a liberdade das aves em bando. A mudança do plano aguarela para os planos da realidade não constituem um quadro vivo. A montagem mostra o paralelismo simbólico dos contrastes. O contraste entre a paleta do pintor, os planos oblíquos e as geometrias da arquitetura moderna. O contraste entre o movimento de um estádio, numa abordagem de análise arquitetónica, o movimento da multidão e a quietude de um estádio pintado. O contraste entre a omnipresença da estátua imóvel e o bulício da cidade. $\mathrm{O}$ contraste entre o deslumbramento dos transeuntes em relação ao ato criativo do pintor e a opressão do polícia representante de um regime que proíbe pequenos ajuntamentos e que, aqui simbolicamente, pode ser um castrador da arte. A autoridade do semáforo impede o fluxo humano do movimento urbano e quando o movimento retoma, a câmara dirige um olhar insistente aos pés das pessoas. 
O cineasta mostra situações quotidianas de uma cidade: dá-nos sequências com a guarda nacional republicana, numa formatura rigorosa e formal entre homens e cavalos à qual se segue uma sequência de miúdos que, com chapéus de papel e armas de madeira, imitam soldados numa formatura imaginária. Um contraste entre poder e liberdade ou um contraste entre autoridade e rebeldia criativa?

Porto da Minha Infância é a simbiose entre a memória e a criação cinematográfica - "tudo ficou esquecido. Na minha triste memória tudo continua vivo". O percurso de planos fixos, a preto e branco, de fotos antigas e a presença ficcional de movimentos de câmara coloridos define o processo proustiano da memória nas sequências da Confeitaria Oliveira, dos passeios depois do jantar pela Avenida das Tílias e da barra dourada onde os boémios falam sobre o futuro. $\mathrm{O}$ percurso da memória encontra o cinema quando o relato do enamoramento pela prima conduz aos momentos Carlitos e Teresinha de Aniki-Bóbó. A relação entre as imagens exige os repetidos "hoje é isto" e "lembro-me".

Manoel de Oliveira senta-se, nestes documentos fílmicos, simbolicamente no estirador de um arquiteto porque define o espaço arquitetónico como um protagonista de tempos e planos, como um espaço estético de uma técnica de montagem. Em $O$ Pintor e a Cidade, a arquitetura escolhe a imagem e o ponto articulador da montagem. A cidade torna-se personagem, título, espaço máximo de reflexão arquitetónica e espaço de reflexão emocional. A cidade é transformada e transforma o olhar da câmara cinematográfica.

Numa entrevista a João Bénard da Costa, na edição comemorativa do seu centenário organizada pela Cinemateca Portuguesa [Oliveira, Costa, 2008: 57], Manoel de Oliveira afirma:

Enquanto Douro é um filme de montagem, o Pintor é um filme de extâses. A gente ficava extasiado com as imagens, por longo tempo. Eu descobri no Pintor que o tempo é um elemento muito importante. Quer dizer, há a cor, há os enquadramentos, há o objeto filmado, mas há sobretudo o tempo sobre eles. Descobri que a imagem rápida tem um efeito, mas a imagem quando persiste ganha outra forma. Comecei a ver coisas 
que não teria visto com movimentos rápidos, com a passagem rápida das imagens. O Pintor e a Cidade é uma obra fundamental na minha carreira, na mudança da minha reflexão sobre o cinema. Porque essa noção de plano longo, extremamente longo, não a fui buscar a nenhum outro filme que conhecia. Não se faziam planos assim, em parte nenhuma do mundo, em nenhuma cinematografia. Em 1956, não se faziam ou eu não os conhecia. (...) realizei um filme sem montagem, a estender-se, a estender-se no tempo em cada uma das tomadas de vista.

\section{$O$ cineasta e a cidade}

No intenso diálogo entre as artes, O Pintor e a Cidade é efetivamente o cineasta e a cidade. E o cineasta e a cidade espelha-se de novo em Douro Faina Fluvial, Aniki-Bóbó e Porto da Minha Infância. A cidade é a protagonista, ao mesmo tempo real e imaginária, passado e presente, rigidez e fluidez, estático e movimento, controlada e controladora, metamorfose e interrogação. Manoel de Oliveira projeta, em $O$ Pintor e a Cidade, simultaneamente o pincel do arquiteto, a câmara do pintor e o estirador do cineasta. Na entrevista a Jacques Parsi encontramos uma fotografia do Porto tirada por Manoel de Oliveira com a afirmação: "É o meu território, noutra parte, seria espectador" [Baecque, Parsi, 1999: 130].

O Porto, em Manoel de Oliveira, constitui-se como a arquitetura do próprio filme. É personagem, título, espaço máximo de reflexão arquitetónica e cinematográfica. O Porto de Manoel de Oliveira é uma cidade montagem, uma cidade plano, uma cidade-enquadramento e uma cidade-movimento de câmara. Tal como o Douro, o Porto de Manoel de Oliveira é a metáfora do próprio cinema. 


\section{Referências bibliográficas}

AAVV (1998), "Manoel de Oliveira", L’Art du Cinéma, 21/22/23, Paris, pp. 9-12; 15-28.

AAVV (2001), "Manoel de Oliveira", Camões. Revista de Letras e Culturas Lusófonas, 12-13, Lisboa, pp. 55-69.

AAVV (2006), "Manoel de Oliveira", Études Cinématographiques, 70, Caen, pp. 7-38; 157-159.

ANDRADE, S. (2008), Ao Correr do Tempo-Duas décadas com Manoel de Oliveira, Portugália Editora, Lisboa.

ARAÚJO, N. (ed.) (2014), Manoel de Oliveira - análise estética de uma matriz cinematográfica, Edições 70, Lisboa.

BAECQUE, A., PARSI, J. (1999), Conversas com Manoel de Oliveira, Campo das Letras, Porto.

CRUZ, J. M. (1996), Manoel de Oliveira e a Montra das Tentações, Publicações Dom Quixote, Lisboa.

JUNQUEIRA, R. S. (org.) (2010), Manoel de Oliveira: uma presença-estudos de literatura e cinema, Editora Perspectiva, São Paulo.

LARDEAU, Y., TANCELIN, P., PARSI, J. (1988), Manoel de Oliveira, Éditions DIS/VOIR, Paris.

LAVIN, M. (2008), La Parole et le Lieu - le cinéma selon Manoel de Olivei$r a$, Presses Universitaires de Rennes, Rennes.

OLIVEIRA, M. (1963), Aniki-Bóbó - planificação do filme de Manoel de Oliveira, Edição do Cine-Clube do Porto, Porto.

OLIVEIRA, A. (2007), "Douro: l'image de Manoel de Oliveira et la voix off d'Agustina Bessa-Luís", Latitudes - Cahiers Lusophones, 29, Paris, pp. 61-64.

OLIVEIRA, A. (2012), "Manoel de Oliveira: o Douro como metáfora", em: Overhoff Ferreira, C. (ed.), Terras em Transe - Ética e Estética no Cinema Português, AVM - Akademische Verlagsgemeinschaft, München, pp. 33-44.

OLIVEIRA, A. (2012), Reencontro Único, Universidade de Trás-os-Montes e Alto Douro, Vila Real.

OLIVEIRA, M., COSTA, J. B. (2008), Manoel de Oliveira. Cem Anos - por Manoel de Oliveira e João Bénard da Costa, Cinemateca Portuguesa Museu do Cinema, Lisboa. 
PINA, M. A. (2012), Aniki-Bóbó, Assírio e Alvim, Lisboa.

PRETO, A. (2008), Manoel de Oliveira - O Cinema Inventado à Letra, Público/Serralves, Lisboa.

\section{Filmografia}

Douro Faina Fluvial, 1931 (documentário 35 mm, 21')

Realização: Manoel de Oliveira

Produção: Manoel de Oliveira

Argumento: Manoel de Oliveira

Fotografia: António Mendes

Som: Mudo

Montagem: Manoel de Oliveira

Aniki-Bóbó, 1942

Realização: Manoel de Oliveira

Produção: António Lopes Ribeiro

Argumento: Manoel de Oliveira inspirado na obra de Rodrigues de Freitas

Os Meninos Milionários

Fotografia: António Mendes

Som: Francisco Mesquita, Mário Malveira.

Montagem: Manoel de Oliveira, Vieira de Sousa

Intérpretes/Personagens: Nascimento Fernandes (lojista), Fernanda Matos

(Teresinha), Horácio Silva (Carlitos), António Santos (Eduardinho), António Morais Soares (Pistarim), Feliciano David (Pompeu), Manuel de Sousa (Filósofo), António Pereira (Batatinhas)

O Pintor e a Cidade, 1956 (documentário 35 mm, 28')

Realização: Manoel de Oliveira

Produção: Manoel de Oliveira

Argumento: Manoel de Oliveira

Fotografia: Manoel de Oliveira

Som: Joaquim Amaral, Alfredo Pimentel

Montagem: Manoel de Oliveira

Intérpretes/Personagens: António Cruz (Pintor) 
Porto da Minha Infância, 2001 (Documentário 35 mm, 62’)

Realização: Manoel de Oliveira

Produção: Madragoa Filmes, Radiotelevisão Portuguesa/RTP

Argumento: Manoel de Oliveira

Fotografia: Emmanuel Machuel

Som: Philippe Morel

Montagem: Valéry Loiseleux

Intérpretes/Personagens: Ricardo Trêpa (Manoel 2), Jorge Trêpa (Manoel 1), Rogério Samora (Chico), Agustina Bessa Luís (Dama texto), José Wallenstein (Joel), Maria de Medeiros (Miss Diabo), Leonor Silveira (Vamp), Leonor Baldaque (Ela) 